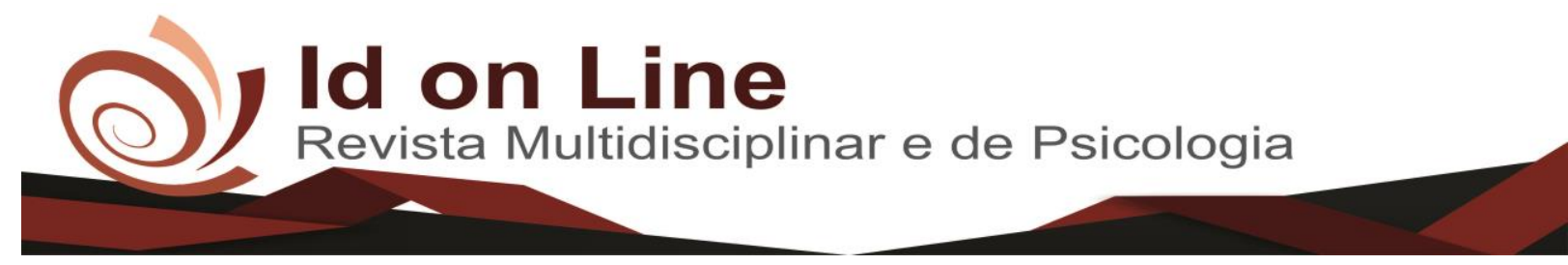

Artigo de Revisão

\title{
Gestão de Pessoas: \\ Agregar, Aplicar, Manter e Avaliar Pessoas ${ }^{1}$
}

\author{
Renata Dantas de Santana. ${ }^{2}$ Thiago Batista Lopes. ${ }^{3}$
}

\begin{abstract}
Resumo: As organizações estão passando por um momento de grandes mudanças e precisam se adaptar às já que, é uma questão de sobrevivência no mercado a busca pela flexibilidade e melhores alternativas de administração e comercialização de seus produtos e/ou serviços. Através da identificação e principalmente manutenção dos colaboradores que se tornam um grande diferencial para a empresa. Neste sentido, é importante pensar como a organização se relaciona com o seu quadro funcional e a partir daí estabelecer linhas internas de ação, seus colaboradores precisam ser respeitados e motivados para que tenham consciência de que auxiliam no alcance de objetivos, e que a união e o esforço conjunto atentam futuramente para o sucesso ou fracasso das mesmas. Deste modo, o presente artigo traz um levantamento bibliográfico, através de uma revisão de literatura acerca dos processos de: agregar, aplicar, manter e avaliar pessoas a luz de autores da área de gestão de pessoas, tema que merece ser discutido e debatido pelas organizações, visto que processos como recrutamento, seleção, treinamento, desenvolvimento, avaliação de desempenhos, remuneração, benefícios e incentivos são assuntos sempre atuais e de grande importância para que as empresas.
\end{abstract}

Palavras-chave: Gestão de pessoas, Avaliar pessoas, Administração.

\section{People management: Agregate, Apply, Maintain and Evaluate People}

\begin{abstract}
The organizations are going through a time of great changes and need to adapt to the already, it is a question of survival in the market the search for flexibility and better alternatives of administration and commercialization of their products and / or services. Through the identification and mainly maintenance of the employees that become a great differential for the company. In this sense, it is important to think about how the organization relates to its functional framework and from there to establish internal lines of action, its employees must be respected and motivated so that they are aware that they help in the achievement of objectives, and that unity and the joint effort in the future for their success or failure. In this way, the present article brings a bibliographical survey through a literature review about the processes of: aggregating, applying, maintaining and evaluating people in the light of authors of the area of people management, a topic that deserves to be discussed and debated by organizations, since processes such as recruitment, selection, training, development, performance evaluation, compensation, benefits and incentives are always current issues and of great importance for companies.
\end{abstract}

Keywords: People management, Evaluating people, Administration.

\footnotetext{
${ }^{1}$ Artigo de Conclusão de Curso da Especialização em Gestão Pública da Universidade do Vale do São Francisco (UNIVASF). ${ }^{2}$ Professora Universitária na ReAGES - Rede de Ensino Ages, na Faculdade Ages de Jeremoabo; Funcionária pública municipal na Prefeitura Municipal de Cícero Dantas (Equipe Técnica PME e PCR); Administradora, especialista em Docência do Ensino Superior e Gestão Hospitalar. Graduanda em Sociologia. Currículo Lattes: http://lattes.cnpq.br/0892646290148911. Contato: renatta_adm@hotmail.com;

${ }^{3}$ Funcionário público municipal na Prefeitura Municipal de Jeremoabo; Contador, especialista em Auditoria e Controladoria de Contas Públicas. Currículo Lattes: http://lattes.cnpq.br/4479888791038921.
} 


\section{Introdução}

Este artigo tem como objetivo descrever as ferramentas disponíveis para os processos de gestão de pessoas, desde a agregação de pessoas até a retenção destas pelas organizações. A área de Gestão de Pessoas é a responsável pela a administração e gerenciamento do capital humano dentro das organizações, deste modo deve baliza-se a luz de teóricos renomados da área para estruturar os processos organizacionais, de modo que propicie uma conduta integra e responsável, respeitando as diferenças e peculiaridades de cada empresa e dos objetivos organizacionais traçados.

Deste modo, verifica-se que a temática nunca deixará de ser discutida, pois, sua conceituação perpassa por gerações. Para Fischer (2002), transformações ocorrem a todo momento no ambiente organizacional, pois as estas absorvem as mudanças do ambiente externos e tem que adapta-se a novas realidades, pois, no cenário atual a economia é globalizada, deste modo, as empresas precisam aprender novos conceitos administrativos e implementa-lo, devido à grande concorrência.

Constata-se que no atual cenário os consumidores estão cada vez mais exigentes e seletivos, fazendo com que as organizações precisem responder de forma rápida e eficiente as demandas dos mesmos, e para que isso ocorra, as empresas precisam ter dentro de suas equipes pessoas comprometidas com os propósitos da organização, para que, as necessidades dos clientes sejam atendidas.

Deste modo, a gestão de pessoas dentro das organizações é uma área estratégica, pois, trabalha com a finalidade de propiciar um ambiente de trabalho mais produtivo, saudável e motivador, unindo os objetivos organizacionais aos individuais, ou seja, equilibrar essa relação empresa $\mathrm{x}$ colaboradores, para que ambos tenham as suas necessidades atendidas.

Neste sentindo, verifica-se que a temática discutida é de grande relevância paras as organizações, pois traz uma revisão de literatura, fazendo uma integração entre autores acerca dos assuntos discutidos. Tendo em vista que conceitos como recrutamento, seleção, treinamento, desenvolvimento, avaliação de desempenho, remuneração, benefícios e incentivos precisam ser debatidos e entendidos para que os processos organizacionais não sejam fragilizados pela não domínio das técnicas. 


\section{Recrutamento e Seleção}

Recrutamento e seleção são atividades que estão interligadas dentro das organizações, cada uma com uma finalidade, completam-se para atingir o objetivo de preencher vagas de trabalho que estão à disposição do público (Chiavenato, 2004).

O recrutamento é a maneira pela qual a organização atrair as pessoas através de anúncios em jornais, internet, sites de recrutamento dentre outros, colocando a disposição das pessoas os cargos a serem preenchidos e as atribuições de tal função, bem como os pré-requisitos para que os recrutados devam possuir para poder participar do processo. Neste sentido, Chiavenato (2004) define recrutamento como:

\footnotetext{
Processo de atrair um conjunto de candidatos para um particular cargo. Ele deve anunciar a disponibilidade do cargo no mercado e atrair candidatos qualificados para disputá-lo. O mercado do qual a organização tenta buscar os candidatos pode ser interno, externo ou uma combinação de ambos. Em outras palavras, a organização deve buscar candidatos dentro dela, fora dela ou em ambos os contextos (CHIAVENATO, 2004, pág. 113).
}

Há três tipos de Recrutamento: Interno e Externo ou Misto. O recrutamento interno é um conjunto de atividades desenhadas para atrair candidatos qualificados para a organização internamente, ou seja, dentro do seu próprio corpo de funcionários, é uma maneira de proporcionar as pessoas à oportunidade de ascender dentro da empresa, também como de proporcionar ao funcionário migrar para uma área que mais se identifica.

O recrutamento externo é um conjunto de atividades desenhadas para atrair candidatos qualificados para a organização no mercado externo, ou seja, pessoas que não fazem parte da organização. O recrutamento misto é a junção do recrutamento interno com o externo. Pode-se visualizar a distinção entre recrutamento interno e recrutamento externo, proposto por Chiavenato (2004), abaixo: 
Quadro 1 - Comparação entre Recrutamento Interno e Externo

\begin{tabular}{|c|c|}
\hline Interno & Externo \\
\hline $\begin{array}{l}\text { - Os cargos vagos são preenchidos por } \\
\text { funcionários, que são selecionados e promovidos } \\
\text { dentro da organização. } \\
\text { - Os candidatos são recrutados internamente } \\
\text { dentro dos quadros da própria organização. } \\
\text { - Os candidatos já são conhecidos pela } \\
\text { organização, passaram por testes de seleção, } \\
\text { passaram por programas de treinamento e forma } \\
\text { avaliados quanto ao seu desempenho. } \\
\text { - As oportunidades de emprego melhor são } \\
\text { oferecidas aos próprios funcionários, que podem } \\
\text { subir a postos melhores e desenvolver sua } \\
\text { carreira profissional dentro da organizacão. }\end{array}$ & $\begin{array}{l}\text { - Os cargos vagos são preenchidos por candidatos } \\
\text { externos que são selecionados e ingressam na } \\
\text { organização. } \\
\text { - Os candidatos são recrutados externamente no } \\
\text { mercado de recursos humanos. } \\
\text { - Os candidatos são desconhecidos pela } \\
\text { organização e precisam ser testados e avaliados } \\
\text { pelo processo seletivo. } \\
\text { - As oportunidades de emprego são oferecidas ao } \\
\text { mercado, cujos candidatos podem disputá-las. }\end{array}$ \\
\hline
\end{tabular}

Fonte: (CHIAVENATO, 2004, pág. 115).

Deste modo, verifica-se a importância das organizações adotarem o tipo de recrutamento que mais se enquadre as suas necessidades e ao tipo de candidato que gostaria de recrutar. Fazendo com que esse processo seja eficaz e que consiga captar profissionais condizentes com a organização.

No que refere-se a seleção está pode ser entendida como o processo pelo qual a organização escolhe o candidato que mais se adequar ao cargo disponibilizado, através de diversas técnicas e de métodos de seleção, dentre elas destacam-se: entrevistas, testes de aptidão, dinâmicas de grupos, testes de conhecimentos etc.

Chiavenato (2004, Pág. 131) define seleção como "processo pelo qual uma organização escolhe de uma lista de candidatos a pessoa que melhor alcança os critérios de seleção para a posição disponível, considerando as atuais condições de mercado".

Neste contexto, o próprio Chiavenato faz uma comparação entre as especificações do cargo ou competências desejadas versus as características dos candidatos. Diz que: "Faz-se uma análise e descrição do cargo para saber quais são os requisitos que o cargo exige de seu ocupante ou definição da competência. Ressaltando as técnicas de seleção para saber quais as condições pessoais para ocupar o cargo ou preencher a competência desejada" (CHIAVENATO, 2004, pág. 132).

Dentro do processo de seleção a empresa fará várias abordagens para colher o máximo de informações a respeito de cada candidato, além de analisar todos os procedimentos dos 
mesmos, verificando se o perfil do mesmo é ou não compatível com o cargo, e com a organização.

\section{Treinamento e Desenvolvimento}

Assim como o Recrutamento e Seleção estão interligados, da mesma forma acontece com o Treinamento e Desenvolvimento. Este é um processo que está interligado: um visando atingir objetivos a curto prazo, enquanto o outro visa atingir resultados a médio e longo prazos.

Treinamento é o "processo de desenvolver qualidades nos recursos humanos para habilitá-los a serem mais produtivos e contribuir melhor para o alcance dos objetivos organizacionais. O propósito do treinamento é aumentar a produtividade dos indivíduos em seus cargos influenciando seus comportamentos" (CHIAVENATO, 2004, pág. 339).

O treinamento é aplicado tendo como objetivo o resultado de curto prazo e aplicado de maneira sistemática e organizada, através do qual as pessoas aprendem conhecimentos, atitudes e habilidades em função de objetivos definidos para poderem executar com esmero as suas atividades dentro da organização.

O treinamento é aplicado com a finalidade de suprir necessidades da organização em curto prazo, e têm a finalidade de capacitar as pessoas. A necessidade de treinamento é percebida quando se faz uma análise e da área de gestão de pessoas da organização, fazendo uma análise dos cargos, bem como uma avaliação de desempenho dos funcionários, visualizase os gargalos, podendo tais fraquezas ser supridas com o treinamento dos funcionários.

Com o treinamento as pessoas acabam refletindo sobre suas posturas dentro e fora da organização e algumas mudanças podem ser percebidas, a figura 1 ilustra algumas mudanças que ocorrem no comportamento das pessoas após a aplicação do treinamento: 
Figura 1: Os quatro tipos de mudanças de comportamento através do treinamento

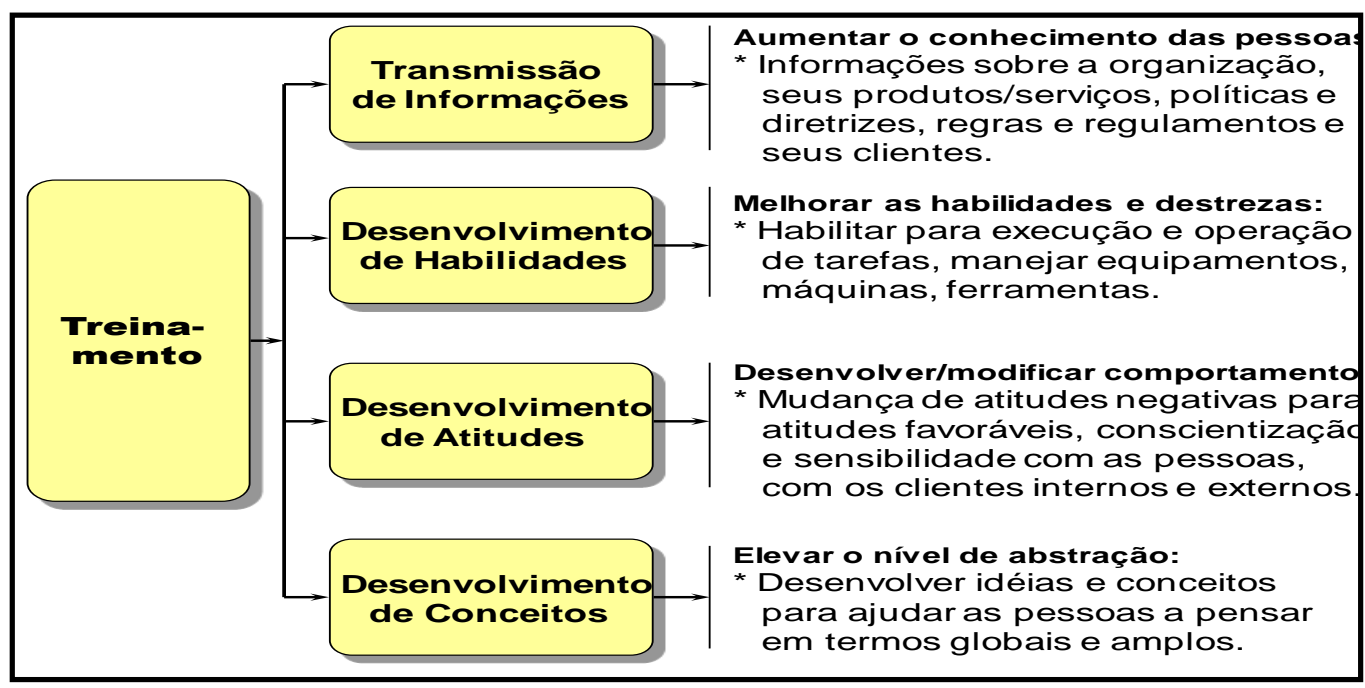

Fonte: (CHIAVENATO, 2004, pág. 340).

O processo de treinamento é indispensável para a integração do novo colaborador a organização, pois, é uma ferramenta utilizada para atingir objetivos a curto prazo, permitindo assim, que o novo membro da organização conheça as suas rotinas, tarefas, responsabilidades e adequando o seu comportamento as práticas da organização.

No que refere-se ao desenvolvimento de pessoas, Chiavenato (2004, pág. 371) define como "conjunto de experiências organizadas de aprendizagem (intencionais e propositais) proporcionadas pela organização, dentro de um específico período de tempo, para oferecer a oportunidade de melhoria do desempenho e/ou do crescimento humano. Inclui três áreas de atividades: treinamento, educação e desenvolvimento".

O desenvolvimento é uma prática que visa desenvolver as pessoas a médio e curto prazo, despertando nas mesmas as suas potencialidades, aumentando as suas competências e habilidades, agregando valor a organização e gerando mais conhecimento para as pessoas. Há algumas formas de desenvolvimento de pessoas, dentre elas pode-se destacar: Rotação de cargos; Posições de assessoria; Aprendizagem prática; Atribuição de comissões; Participação em cursos e seminários externos; Exercícios de simulação; Treinamento (outdoor) fora da empresa; Estudo de casos; Jogos de empresas; Centros de desenvolvimento internos; Coaching; Mentoring e Tutoria e Aconselhamento de funcionários. 
O desenvolvimento de pessoas é uma forma das organizações investirem em seus colaboradores, de forma a torná-los mais habilidosos, e que tenham mais conhecimento, melhorando cada vez mais o desempenho no cargo qual ocupa.

\section{Avaliação de Desempenho}

A avaliação de desempenho é uma técnica de gestão utilizada nas organizações desde os tempos mais remotos até os dias atuais, pois é de fundamental importância para o sucesso das mesmas. Sendo que através desta técnica pode-se mensurar o trabalho de seus colaboradores como também o ambiente de trabalho organizacional, possibilita aos gestores uma visão do trabalho do seu colaborador e como os mesmos estão executando as suas atividades, a avaliação de desempenho proporciona uma retroalimentação positiva ou negativa do trabalho que está sendo executado (GIL, 1994).

Deste modo, a avaliação de desempenho pode ser considerada como uma apreciação crítica do desempenho de cada colaborador, e como o mesmo desempenha as suas atividades dentro da organização, ressaltando sobre tudo qual a contribuição que cada funcionário oferece a organização.

Neste contexto, a avaliação de desempenho é uma mensuração do trabalho de cada funcionário, levando em conta as atribuições do cargo e as atividades desempenhadas pelos mesmos, ou seja, é uma análise entre o desempenho padrão/esperado e o real. Portanto, a avaliação de desempenho é uma técnica que analisa as atividades passadas, visando corrigir e aperfeiçoar o trabalho de cada colaborador, visando no futuro alcançar todo o potencial humano da organização (CHIAVENATO, 2004).

Gil (1994), afirma que a avaliação de desempenho é como uma ponte que liga a expectativa do empregador quanto ao preenchimento de determinado cargo, ao desempenho real do empregado. Bergamini (1998) completa que a avaliação de desempenho nas organizações constitui-se, portanto, no veículo da estimativa do aproveitamento do potencial individual das pessoas no trabalho e, por isso, do potencial humano de toda a empresa.

Pode-se perceber que a avaliação de desempenho é mais do que uma técnica capaz de mensurar resultados e desempenhos dos seus colaboradores, é uma prática que permite ao gestor uma visão geral de toda organização. Permite detectar as fragilidades de cada funcionário e como o mesmo desempenha as suas atividades, permitindo a organização detectar o que o mesmo faz e o que a organização espera que o faça.

Desde que o homem começou a trabalhar para outro, passou a ser monitorado e avaliado com base em suas habilidades e competências individuais, ressaltando o esforço feito para a 
execução de tal tarefa. Nesse contexto, percebe-se que as práticas de avaliação de desempenho não são novas, e que são utilizadas como um sistema de recompensa, se o trabalho estiver sendo realizo a contento do empregador ou como uma punição se o trabalho não estiver sendo executado como o esperado.

Há vários métodos de avaliação de desempenho utilizados pelas organizações para mensurar o trabalho dos seus colaboradores, dentre eles os mais utilizados são: Listas de Verificação; Escalas Gráficas; Pesquisa de Campo; Escolha Forçada; Métodos dos Incidentes Críticos; Avaliação para cima; Auto-avaliação; Avaliação $360^{\circ}$ e Avaliação participativa por Objetivos.

\section{Escalas Gráficas}

É o método de Avaliação de desempenho mais utilizado pelas organizações, por ser de fácil compreensão e aplicação, porém exige do avaliador cautela e impessoalidade a fim de evitar préjulgamentos e opiniões pessoais. Consiste-se num método que avalia o desempenho dos colaboradores através de fatores de avaliação previamente definidos e graduados, estabelecendo os aspectos a serem analisados como as variações e tais aspectos de competências e habilidades em cada aspecto. Chiavenato (2004) elenca os prós e os contras do método de avaliação de desempenho escalas gráficas:

Quadro 2: Prós e Contras do método de avaliação de desempenho Escalas gráficas

\begin{tabular}{|c|c|}
\hline Prós & Contras \\
\hline 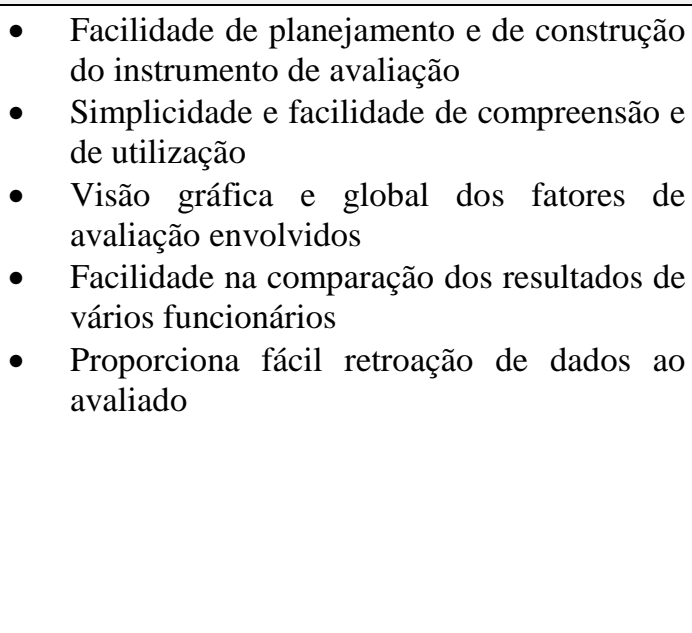 & $\begin{array}{l}\text { - Superficialidade e subjetividade na avaliação do } \\
\text { desempenho } \\
\text { - Produz efeito de generalização (hallo effect): se } \\
\text { o avaliado recebe bom em um fator, } \\
\text { provavelmente receberá bom em todos os } \\
\text { demais fatores } \\
\text { - Perca pela categorização e homogeneização das } \\
\text { características individuais } \\
\text { - Limitação dos fatores de avaliação: funciona } \\
\text { como sistema fechado } \\
\text { - Rigidez e reducionismo no processo de } \\
\text { avaliação } \\
\text { Nenhuma participação ativa do funcionário } \\
\text { avaliado } \\
\text { Avalia apenas o desempenho passado }\end{array}$ \\
\hline
\end{tabular}

Fonte: (CHIAVENATO, 2004, pág. 231). 


\section{Escolha forçada}

É o método de avaliação que advém em avaliar o desempenho dos indivíduos por intermédio de frases descritivas e determinadas alternativas de tipos de desempenho individual. Em cada bloco, ou conjunto composto de duas, quatro ou mais frases, o avaliador deve escolher, forçosamente, apenas uma ou duas alternativas, que mais se aplicam ao desempenho do empregado avaliado. Os blocos são formados por duas frases de significado positivo e de duas de significado negativo. $\mathrm{O}$ avaliador, ao julgar o empregado, escolhe a frase que mais se aplica e a que menos se aplica ao desempenho do avaliado, eliminando assim a superficialidade e a generalização. Neste contexto Chiavenato (2004) ressalta os pós e contras do método de escolha forçada:

Quadro 3: Prós e Contras do método de avaliação de desempenho Escolha Forçada

\begin{tabular}{|c|c|}
\hline Prós & Contras \\
\hline $\begin{array}{l}\text { - } \quad \text { Evita o efeito de generalização (hallo effect) } \\
\text { na avaliação } \\
\text { - } \quad \text { Tira à influência pessoal do avaliador, isto é } \\
\text { a subjetividade } \\
\text { - } \quad \text { Não requer treinamento dos avaliadores para } \\
\text { a sua aplicação }\end{array}$ & $\begin{array}{l}\text { - Complexidade no planejamento e na } \\
\text { construção do instrumento } \\
\text { - Não proporciona visão global dos resultados } \\
\text { da avaliação } \\
\text { - Não provoca retroação de dados, nem } \\
\text { permite comparações } \\
\text { - Técnica pouco conclusiva a respeito dos } \\
\text { dados } \\
\text { - Nenhuma participação ativa do avaliado }\end{array}$ \\
\hline
\end{tabular}

Fonte: (CHIAVENATO, 2004, pág. 233).

\section{Pesquisa de Campo}

O método de avaliação desempenho pesquisa de campo é considerado um dos mais completos, por permite uma visão holística da organização, como também por ter a participação de todo o quadro funcional. É realizado pelo chefe, com assessoria de um especialista staff. Permite uma análise profunda do clima organizacional, pois, tem uma interação com cada funcionário, podendo assim colher dados relevantes e percepções de cada subordinado sobre a organização. Segundo Chiavenato (2004) o método está dividido em quatro etapas, são elas: entrevista de avaliação inicial, entrevista de analise complementar, planejamento das providencias e acompanhamento posterior dos resultados. Nesta perspectiva Chiavenato (2004) coloca os prós e contras do método de avaliação de desempenho pesquisa de campo: 
Quadro 4: Prós e Contras do método de avaliação de desempenho Pesquisa de Campo

\begin{tabular}{|c|c|}
\hline Prós & Contras \\
\hline $\begin{array}{l}\text { - Envolve responsabilidade de linha (o gerente } \\
\text { avalia) e função de staff (o DRH assessorar) } \\
\text { na avaliação de desempenho } \\
\text { - Permite planejamento de ações para o futuro } \\
\text { (como programas de treinamento, orientação, } \\
\text { aconselhamento e etc) } \\
\text { - Enfatiza a melhoria de desempenho e alcance } \\
\text { de resultados } \\
\text { - Proporciona profundidade na avaliação do } \\
\text { desempenho } \\
\text { - Permite relação proveitosa entre gerente de } \\
\text { linha e especialista de staff }\end{array}$ & $\begin{array}{l}\text { - Custo operacional elevado por exige a } \\
\text { assessoria de especialista } \\
\text { - Processo de avaliação lento e demorado } \\
\text { - Pouca participação do avaliado, tanto na } \\
\text { avaliação como nas providencias }\end{array}$ \\
\hline
\end{tabular}

Fonte: (CHIAVENATO, 2004, pág. 234).

\section{Métodos de Incidentes Críticos}

Tem como principal foco de avaliação o comportamento do individuo, porém não avalia os aspectos normais e sim comportamentos fora do padrão positivos ou negativos. É uma técnica sistemática, por meio da qual o supervisor imediato observa e registra os fatos excepcionalmente positivos e os fatos excepcionalmente negativos a respeito do desempenho dos seus subordinados. Focaliza tanto as exceções positivas como as negativas no desempenho de cada colaborador. Neste sentido Chiavenato (2004) elenca os prós e contras do método de avaliação de desempenho incidente críticos:

Quadro 5: Prós e Contras do método de avaliação de desempenho Incidente Críticos

\begin{tabular}{|l|ll|}
\hline \multicolumn{1}{|c|}{ Prós } & \multicolumn{1}{c|}{ Contras } \\
\hline - $\begin{array}{l}\text { Avalia o desempenho excepcionalmente bom } \\
\text { e o excepcionalmente ruim }\end{array}$ & $\bullet \begin{array}{l}\text { Não se preocupa com aspectos normais do } \\
\text { desempenho }\end{array}$ \\
- Enfatiza os aspectos excepcionais do \\
desempenho. As exceções positivas devem \\
$\begin{array}{l}\text { ser realçadas e bem mais aplicadas, enquanto } \\
\text { exceções negativas devem ser eliminadas ou } \\
\text { corrigidas }\end{array}$
\end{tabular}$\quad \begin{aligned} & \begin{array}{l}\text { Perca por fixasse em poucos aspectos do } \\
\text { desempenho. Dando sua tendenciosidade } \\
\text { sua parcialidade. }\end{array} \\
& \begin{array}{l}\text { Método de fácil montagem e de fácil } \\
\text { utilização }\end{array}\end{aligned}$

Fonte: (CHIAVENATO, 2004, pág. 235). 


\section{Lista de Verificação}

É um método simples e prático em que os gestores podem estar avaliando os seus subordinados diariamente, fazendo anotações sobre o comportamento dos mesmos. É considerado a forma concisa do método de escalas gráficas, como também é usado como suporte para os demais métodos de avaliação.

\section{Avaliação 360}

A avaliação $360^{\circ}$ consiste na técnica de que o funcionário é avaliado de forma circular, ou seja, por todos que trabalham diretamente com o mesmo, fazendo com que o mesmo seja avaliado por todos os colegas de trabalho. Assim o avaliador terá várias visões a respeito do funcionário com diversas percepções dos seus colegas, superiores, clientes internos e externos e fornecedores.

A avaliação $360^{\circ}$ tem características peculiares, pois o funcionário tem que estar preparado para ouvir e assimilar os que outros têm a dizer, lidando com tal situação de forma ética e impessoal, fazendo com que não gere conflitos e um clima desfavorável.

\section{Avaliação para cima}

A avaliação para cima é o inverso da avaliação $360^{\circ}$, consiste na técnica de que a equipe de trabalho avalia o seu superior imediato. Isso faz com que os gestores tenham uma relação com a sua equipe, quanto à alta cúpula possa avaliar o trabalho dos gerentes, ou das pessoas que ocupam cargos de chefia.

\section{Auto avaliação}

A auto-avaliação é uma técnica em que o funcionário vai auto avaliar-se, fazendo com que os funcionários descrevam os seus pontos fortes e os seus pontos fracos. Essa modalidade de avaliação faz com que o funcionário possa descrever sobre o seu desempenho profissional em um espaço de tempo, porém, todas as informações relatadas têm que ser verificadas por o seu superior imediato. 


\section{Avaliação Participativa por objetivos (APPO)}

A avaliação Participativa por objetivos (APPO) é uma melhoria da administração por objetivos (APO), é uma técnica que busca integrar todos os membros que compõem a organização fazendo com que todas as atividades a serem desempenhadas e que todas as decisões a serem tomadas sejam debatidas e discutidas por toda a equipe, fazendo com que todos participem ativamente das atividades organizacionais, sentindo-se responsável pelo o sucesso ou fracasso da mesma.

Sendo assim, a avaliação de desempenho deve ser utilizada por todas as organizações independente do seu porte para assim melhorar a sua eficiência e a sua eficácia. A avaliação de desempenho serve como uma maneira da organização recompensar ou punir o seu funcionário conforme o seu desempenho, destacando os pontos fortes e fracos de cada um, dando-lhes um retorno de suas atividades, além de dar um suporte aos pontos fracos, para que os mesmos possam melhorar. Os métodos descritos acima são os mais utilizados pelas organizações modernas, cabendo as mesmas utilizarem o que mais se enquadram ao seu porte.

\section{Remuneração, Benefícios e Incentivos}

Com o advento do capitalismo, as relações de trabalho passaram a ser baseadas em uma contrapartida do empregador para com o empregado, ou seja, o pagamento de uma remuneração pelo serviço prestado. A remuneração consiste, em uma forma de recompensar os funcionários pelo trabalho realizado, estas recompensas podem ser financeiras e não-financeiras. Neste sentido, Lacombe (2005) conceitua remuneração como:

Remuneração é a soma de tudo o que é periodicamente pago aos empregados por serviços prestados: salários, gratificações, adicionais (por periculosidade, insalubridade, tempo de serviço, trabalho noturno e horas extras), bem como todos os benefícios financeiros, como prêmios por produtividade, participação nos resultados e opção de compras de ações entre outros (LACOMBE, 2005, pág. 147).

Chiavenato (2004, pág. 260) completa que: a remuneração é um "processo que envolve todas as formas de pagamento ou de recompensas dadas aos funcionários e decorrentes do seu emprego".

A remuneração dos colaboradores pode ser dividida em três níveis remuneração básica, incentivos e benefícios, os quais formam a remuneração total. A remuneração também pode ser 
fixa ou variável, requisito esse que depende da política salarial da organização, e da sua estrutura de salários.

A remuneração fixa é a forma de remuneração mensal, conforme critérios previamente definidos pela organização é uma forma de remuneração que reduz os riscos na relação empregadores e empregados. A remuneração variável é paga com base nos resultados apresentados pelo empregado, sendo este o fator chave para a sua remuneração. Chiavenato (2004) aborda os prós e contras da remuneração fixa e da remuneração variável:

Quadro 6: Prós e contras do sistema de remuneração fixa

\begin{tabular}{|c|c|}
\hline Prós & Contras \\
\hline $\begin{array}{l}\text { - Facilita o equilíbrio interno (consistência dos } \\
\text { salários dentro da organização) e o equilíbrio } \\
\text { externo (consistência dos salários da } \\
\text { organização com os do mercado). } \\
\text { - Homogeneíza e padroniza os salários dentro } \\
\text { da organização. } \\
\text { - Facilita a administração dos salários e o seu } \\
\text { controle centralizado. } \\
\text { - Permite uma base lógica e racional para a } \\
\text { distribuição dos salários. } \\
\text { Focaliza a execução das tarefas e a busca da } \\
\text { eficiência. } \\
\text { Afeta diretamente os custos fixos da } \\
\text { organização. }\end{array}$ & $\begin{array}{l}\text { - Não apresenta motivação intrínseca: funciona } \\
\text { - } \quad \text { Não incentiva o espírito empreendedor, nem } \\
\text { a aceitação de riscos e responsabilidades. } \\
\text { - } \quad \text { Funciona como elemento de conservação da } \\
\text { rotina e do status quo. } \\
\text { - Remunera as pessoas em função do tempo } \\
\text { disponibilizado e não pelo desempenho ou } \\
\text { pelo alcance de metas ou resultados. }\end{array}$ \\
\hline
\end{tabular}

Fonte: (CHIAVENATO, 2004, pág. 291-292).

Quando 7: Prós e contras do sistema de remuneração variável

\begin{tabular}{|c|c|}
\hline Prós & Contras \\
\hline 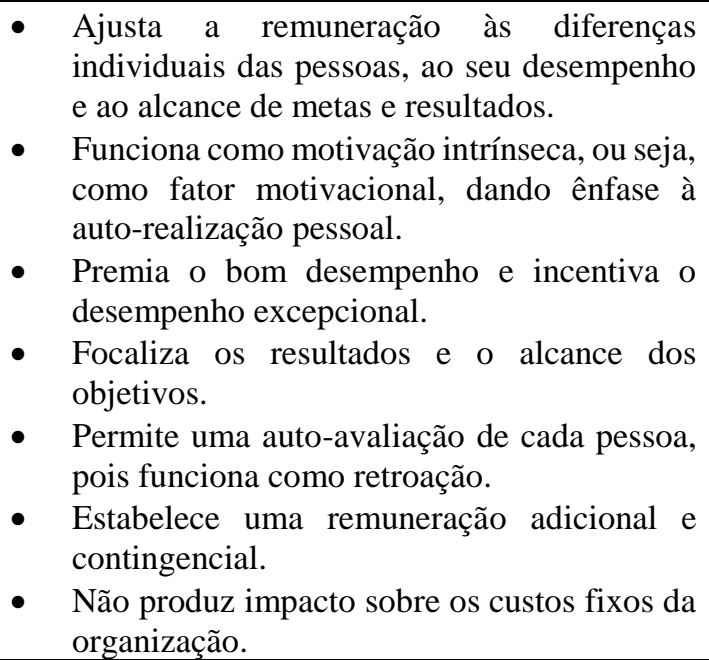 & 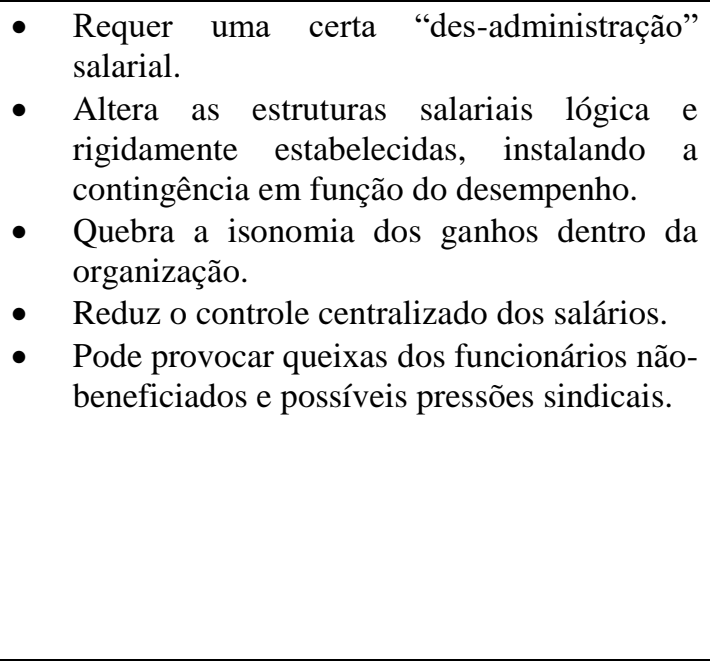 \\
\hline
\end{tabular}

Fonte: (CHIAVENATO, 2004, pág. 291-292). 
Pode-se perceber que a forma de remuneração, seja ela fixa ou variável dependerá da política salarial da organização, do seu ramo de atividade e da sua estrutura organizacional, cabendo ao empregador definir qual se encaixa melhor ao perfil organizacional.

Outro componente da remuneração total são os benefícios concedidos aos funcionários pela organização. Benefícios são certas regalias e vantagens concedidas pelas organizações, a título de pagamento adicional aos salários à totalidade ou a parte de seus funcionários (CHIAVENATO, 2004, pág. 314). Neste sentido Araujo (2006, pág. 169), completa que "os benefícios sociais são incentivos internos oferecidos com o objetivo de satisfazer às necessidades pessoais, proporcionando um ambiente mais harmonioso possível e produtivo para toda a organização, correspondem às condições de trabalho que as organizações oferecem para manter as pessoas".

Os benefícios sociais fazem parte dos atrativos oferecidos pelas organizações para reter e manter os seus funcionários, a vários tipos de benefícios concedidos aos funcionários, e classificam-se quanto à sua exigibilidade legal, quanto a sua natureza e quanto aos seus objetivos (CHIAVENATO, 2004, pág. 315).

Como já mencionado um dos tipos de benefícios são quanto a sua exigibilidade legal, dentro desta categoria encontram-se os benefícios legais e os benefícios espontâneos. Os benefícios legais podem ser conceituados como aqueles que atendem as legislações trabalhistas e previdenciárias, os quais a organização tem obrigação de ofertar, porém algumas são de responsabilidade de órgãos previdenciários (CHIAVENATO, 2004, pág. 316).

Os benefícios espontâneos podem ser entendidos como aqueles oferecidos de forma voluntária pela organização, sem nenhuma exigência legal. Cabendo a organização a decisão de ofertá-los ou não.

Quadro 8: Exemplos de benefícios (legais e espontâneos)

\begin{tabular}{|c|c|}
\hline Benefícios Legais & Benefícios Espontâneos \\
\hline $\begin{array}{ll}\text { - } & \text { Férias } \\
\text { - } & 13^{\circ} \text { salário } \\
\text { - } & \text { Aposentadoria } \\
\text { - } & \text { Seguro de acidentes do trabalho } \\
\text { - } & \text { Auxilio doença } \\
\text { - } & \text { Salário família } \\
\text { - } & \text { Salário maternidade } \\
\text { - } & \text { Etc. }\end{array}$ & $\begin{array}{ll}\text { - } & \text { Gratificações } \\
\text { - } & \text { Refeições subsidiadas } \\
\text { - } & \text { Transporte subsidiado } \\
\text { - Seguro de vida em grupo } \\
\text { - } \\
\text { - } \quad \text { Assistếstimos aos funcionários médico-hospitalar diferenciada } \\
\text { mediante convênio } \\
\text { - Complementação de aposentadoria ou planos } \\
\quad \text { de seguridade social }\end{array}$ \\
\hline
\end{tabular}

Fonte: (CHIAVENATO, 2004, pág. 316). 
Os benefícios também são classificados quanto a sua natureza, podendo estes serem monetários e não-monetários. Os monetários são benefícios concedidos em dinheiro, gerando encargos na folha de pagamento (CHIAVENATO, 2004, pág. 316). Os benefícios nãomonetários são concedidos em forma de serviços ou de vantagens para o funcionário.

Quadro 9: Exemplo de Benefícios Monetários e Não-monetários

\begin{tabular}{|c|c|}
\hline Benefícios Monetários & Benefícios não-monetários \\
\hline $\begin{array}{lll}\text { - } & \text { Férias } \\
\text { - } & 13^{\circ} \text { salário } \\
\text { - } & \text { Gratificações } \\
\text { - } & \text { Complementação do salário nos } \\
& \text { afastamentos prolongados por doença } \\
\text { - } & \text { Etc. }\end{array}$ & $\begin{array}{ll}\text { - } & \text { Refeitório } \\
\text { - } & \text { Assistência médico-hospitalar } \\
\text { - } & \text { Assistência odontológica } \\
\text { - } & \text { Serviço social e aconselhamento } \\
\text { - } & \text { Clube ou grêmio } \\
\text { - } & \text { Transporte de casa para a empresa e vice- } \\
& \text { versa } \\
\text { - Horário móvel ou flexível } \\
\text { - } & \text { Etc. }\end{array}$ \\
\hline
\end{tabular}

Fonte: (CHIAVENATO, 2004, pág. 316).

Concluindo as classificações dadas aos benefícios, temos os benefícios quanto aos seus objetivos, que pode ser: benefícios assistencialistas, recreativos e supletivos. Os benefícios assistencialistas são aqueles que visam suprir emergências, proporcionando ao funcionário e sua família uma maior segurança e bem-estar, pois sabe que estará respaldado caso ocorra algum imprevisto. Os benefícios recreativos podem ser entendidos como benefícios que visam proporcionar ao colaborador atividades de lazer, repouso, diversão, esporte, podendo estender tais as suas famílias. E por ultimo os benefícios supletivos que visam proporcionar aos funcionários certas conveniências e ações que melhorem a qualidade de vida dos seus colaboradores (CHIAVENATO, 2004, pág. 316-317).

Quadro 10: Exemplos de Benefícios Assistenciais, Recreativos e Supletivos

\begin{tabular}{|c|c|c|}
\hline Benefícios Assistenciais & Benefícios Recreativos & Benefícios Supletivos \\
\hline $\begin{array}{ll}\text { - } & \text { Assistência médico } \\
\text { hospitalar } \\
\text { - } & \text { Assistência Odontológica } \\
\text { - } & \text { Assistência financeira } \\
& \text { Através de empréstimos } \\
\text { - } & \text { Serviço Social }\end{array}$ & $\begin{array}{l}\text { - } \text { Grêmio ou clube } \\
\text { - Áreas de lazer nos } \\
\text { intervalos de trabalho } \\
\text { - } \text { Música ambiente } \\
\text { - Atividades esportivas e } \\
\text { comunitárias } \\
\text { - Passeios e excursões } \\
\text { programas e etc. }\end{array}$ & $\begin{array}{ll}\text { - } & \text { Transporte } \\
\text { - } & \text { Restaurante no local de } \\
& \text { trabalho } \\
\text { - } & \text { Estacionamento privativo } \\
\text { - } & \text { Horário móvel de } \\
& \text { trabalho }\end{array}$ \\
\hline
\end{tabular}




\begin{tabular}{|l|l|l|}
\hline $\begin{array}{l}\text { Complementação da } \\
\text { aposentadoria ou planos } \\
\text { de previdência social }\end{array}$ & $\begin{array}{l}\text { Cooperativa de gêneros } \\
\text { alimentícios ou convênio } \\
\text { com supermercados }\end{array}$ \\
$\begin{array}{l}\text { Seguro de vida em grupo } \\
\text { ou de acidentes pessoais } \\
\text { Creche para filhos de } \\
\text { funcionários e etc. }\end{array}$ & Agência bancária no local \\
de trabalho e etc.
\end{tabular}

Fonte: (CHIAVENATO, 2004, pág. 316-317).

Pode-se observar que nos dias atuais as organizações precisam oferecer aos seus colaboradores, não apenas a remuneração como pagamento do serviço prestado, e sim benefícios e incentivos que contribuam para a motivação das mesmas. Neste sentido, que os programas de incentivos contribuem para a melhoria do desempenho de cada funcionário, pois, faz com que os mesmos busquem cada vez mais superar os seus limites e com isso ajude para o crescimento da organização.

Neste sentido, as organizações estão oferecendo aos seus colaboradores recompensas, que fazem com que os funcionários busquem a melhoria continua do seu trabalho, pois, sabe que o sucesso da organização esta atrelado ao seu sucesso pessoal. Chiavenato (2004) enfatiza que as recompensas organizacionais são oferecidas para reforçar as atividades que produzem os seguintes efeitos:

1. Aumentem a consciência e responsabilidade do individuo e do grupo dentro da organização. Isto é, que incentivem o espírito de missão na empresa.

2. Ampliem a interdependência do individuo para com o grupo e do grupo para com toda a organização. Em outras palavras, incentivem o espírito de equipe e o trabalho em conjunto.

3. Ajudem a enfatizar a constante criação de valor dentro da organização. Em outras palavras, incentivem as ações que agreguem valor à organização, ao cliente e às próprias pessoas. O desempenho excelente deve ser premiado (CHIAVENATO, 2004, pág. 289).

Os programas de incentivos como são chamados podem ser uma maneira da organização está recompensando o seu colaborador, complementando a sua remuneração monetária e proporcionando aos mesmos uma maior segurança e bem-estar. Neste sentido, Chiavenato (2004) ressalta que: 
Quadro 11: Tipos de Recompensas

\begin{tabular}{|c|c|}
\hline $\begin{array}{l}\text { 1. Recompensas relacionadas com os objetivos } \\
\text { de relação empresarial - como o lucro ou o prejuízo }\end{array}$ & $\begin{array}{l}\text { 2. Recompensas vinculadas ao tempo de serviço } \\
\text { do funcionário }\end{array}$ \\
\hline $\begin{array}{l}\text { A participação nos resultados anuais ou semestrais é } \\
\text { um exemplo desse critério. Embora ainda limitadas a } \\
\text { certos níveis, como diretores e gerentes, esse critério } \\
\text { encerra potencialmente um forte impacto } \\
\text { motivacional. }\end{array}$ & $\begin{array}{l}\text { E que são concedidas automaticamente em certos } \\
\text { intervalos, como } 5 \text { ou } 10 \text { anos, desde que o funcionário } \\
\text { não tenha tido um desempenho insatisfatório. Os } \\
\text { chamados qüinqüênios ou decênios são exemplos } \\
\text { desse critério. Tais incentivos são relativamente } \\
\text { pequenos e buscam principalmente manter o equilíbrio } \\
\text { salarial. }\end{array}$ \\
\hline $\begin{array}{l}\text { onadas com o desempenho } \\
\text { nal }\end{array}$ & $\begin{array}{l}\text { 4. Recompensas relacionadas com resultados } \\
\text { departamentais, divisionais ou mesmo globais }\end{array}$ \\
\hline $\begin{array}{l}\text { Essas recompensas exigem apenas diferenciação no } \\
\text { desempenho e melhorias salariais com valor } \\
\text { motivacional. É o aumento por mérito. }\end{array}$ & $\begin{array}{l}\text { Objetivamente quantificáveis. Podem ser } \\
\text { compartilhadas dentro do grupo, em termos de igual } \\
\text { porcentagem com relação à base salarial de cada } \\
\text { pessoa. É a chamada remuneração variável. }\end{array}$ \\
\hline
\end{tabular}

Fonte: (CHIAVENATO, 2004, pág. 380).

\section{Conclusão}

Constatou-se após a realização da pesquisa que área de gestão de pessoas é uma temática que merece ser debatida pelas de forma continua, visto que, os processos de agregar, aplicar, manter e avaliar pessoas é cíclico, ou seja, as organizações nunca deixarão de fazer, pois, é necessário para a continuidade da organização e renovação do seu quadro de colaboradores, para que os objetivos organizacionais estejam sempre alinhados aos objetivos individuais de cada colaborador seja este, novato ou veterano.

Deste modo a área de gestão de pessoas é responsável por disseminar a cultura organizacional, gerir o clima e os conflitos organizacionais, tendo processos de recrutamento, seleção, treinamento, desenvolvimento, avaliação de desempenho, remuneração, benefícios e incentivos condizentes com a estrutura organizacional, fazendo com que os colaboradores sintam-se parte da equipe, e que o trabalho desenvolvido agrega ao desempenho da organização.

\section{Referências}

ARAUJO, Luis César G. de. Gestão de Pessoas. São Paulo: Atlas, 2006. 
BERGAMINI, Cecília Whitaker; BERALDO, Deobel Ramos. Avaliação de desempenho humano na empresa. 4. ed. São Paulo: Atlas, 1998.

BOHLANDER, George W; SNELL, Scott; SHERMAN, Arthur. Administração de Recursos Humanos. Trad. Maria Lúcia G. Leite Rosa. São Paulo: Pioneira Thomson Learning, 2003.

CHIAVENATO, Idalberto. Comportamento Organizacional. Rio de Janeiro: Elsevier, 2005. Idalberto. Gestão de Pessoas: O novo papel dos recursos humanos nas organizações. Rio de Janeiro: Elsevier, 1999.

, Ialberto. Gestão de Pessoas: O novo papel dos recursos humanos nas organizações. Rio de Janeiro: Elsevier, 2004.

, Idalberto. Gerenciando com as Pessoas. Rio de Janeiro: Elsevier, 2004.

, Idalberto. Recursos Humanos: o capital humano das organizações. São Paulo:

Atlas, 2004.

GIL, A. C. Administração de recursos humanos: um enfoque profissional. São Paulo: Atlas, 1994.

LACOMBE, Francisco José Masset. Recursos Humanos: princípios e tendências. São Paulo: Saraiva 2005.

RIBEIRO, Antonio de Lima. Gestão de Pessoas. São Paulo: Saraiva 2005.

ROBBINS, Stephen P. Comportamento Organizacional. Trad. Reynaldo Marcondes. São Paulo: Pearson Prentise Hall, 2005.

VERGARA, Sylvia Constant Vergara. Gestão de Pessoas. São Paulo: Atlas, 2006.

TACHIZAWA, Takeshy; FERREIRA, Victor Cláudio Paradela; FORTUNA, Antônio Alfredo Mello. Gestão com Pessoas. Rio de Janeiro: Editora FGV, 2001.

WAGNER III, John A; Hollenbeck, John R. Comportamento Organizacional. Trad.: Cid Knipel Moreira. São Paulo: Saraiva, 2004.

Como citar este artigo (Formato ABNT):

SANTANA, Renata Dantas de; LOPES, Thiago Batista. Gestão de Pessoas: Agregar, Aplicar, Manter e Avaliar Pessoas. Id on Line Rev.Mult. Psic., 2018, vol.12, n.42, p. 261-278. ISSN: 1981-1179.

Recebido: 04/09/2018;

Aceito: 06/09/2018 